\title{
MIRÁNDONOS PARA BUSCAR SENTIDO
}

Norma Constanza Castaño, Guillermo Chona, Jorge Emiro Pinzón, Luis Lara, Edgar Valbuena, Silvia Martínez, Mireya Leudo, Judith Arteta de Molina, Guido Moncayo y Daniel Herrera

«Oubliez tout de que vous avez appris.

Commendez pour rêver» ${ }^{1}$

(Paredes de París. Mayo de 1968).

\begin{abstract}
A first approach of the research is done. The analysis of the Biology teacher's in formation, characteristics with his/her results, is contributing to the curricular program at the licentiate in Biology. This project tries to be near the imaginative visions that the current students have in relation to emotional, social, educational, political and cultural aspects.

The first stage of the research shows the perspective that we have constructed around aspects such as (religion, politics and art), the family, sexuality, expectancy of life, intellectual development, education (pedagogy, research, conceptions about teachers, the teacher's training and the program itself). The second stage will show what the teachers think about; what we think about them and what the other teachers think and feel. Similarly, a confrontation with theory related to it will be done; finally the achievements will be analyzed in a critical way, and the necessary perspective will be done to construct a curricular project in the Licentiate of Biology.
\end{abstract}

\section{PALABRAS CLAVES}

Analfabetismo cultural, cultura, educación, expectativas de vida, familia, formación de maestros, heteronomia, individualismo, imaginarios, política, religiosidad, visión local.

\section{ANTEDEDENTES}

Desde el segundo semestre de 1995 el propósito del Comité de Práctica ha sido contribuir a la construcción del proyecto pedagógico del Departamento de Biología de

\footnotetext{
* Los profesores mencionados forman parte del Comité de Práctica Pedagógica del Departamento de Biología y se contó con la colaboración activa de la estudiante Olga Riveros y del profesor Norberto Bohórquez.

1 "Olvidad todo lo que habéis aprendido Comenzad por soñar".
} 
modo que el ejercicio docente tenga sentido para los maestros en formación. Se empezó a hacer un análisis critico del área de formación pedagógica y de la práctica docente, se propuso analizar la realidad que viven los estudiantes tanto en la carrera como en la práctica en la escuela y al mismo tiempo propiciar al interior del Comité, la comunicación, el intercambio de ideas, la confrontación de pensamientos Creíamos que desde esta óptica seria posible empezar a concretar la idea de lo que en ese momento llamábamos proyectos pedagógicos y construir conocimiento alrededor de ellos.

Estos propósitos se fundamentan en el planteamiento de que "la educación como acción que caracteriza a lo humano, implica una constancia intencional y colectiva;... que no hay educación sin compromiso, sin intencionalidad, sin finalidades (pero enfatizamos además que) la educación no constituye sólo actividad, uso, hábito, exterioridad sino también interioridad, creación, reflexión, compromiso... La acción educativa es una acción moral, tiene un sentido de intersubjetividad, un modo de 'ser con los otros'?

En un análisis preliminar planteamos que no hay una cultura de la pedagogía y de la didáctica en el Departamento de Biología, el trabajo que se hace en general es intuitivo, asistemático y esto se ve reforzado por la falta de comunicación de las experiencias y de debate, no hay tampoco una cultura de la comunicación y por eso es urgente empezar a construirla" ${ }^{3}$. Se hizo necesario mostrar a los estudiantes el valor de la profesión docente, y esto se pensó podría lograr posibilidades de transformación y de cambio del maestro en la escuela; presentar la docencia como un reto y la pedagogía como investigación.

En el primer semestre de 1996 el énfasis del trabajo del Comité de Práctica fue el análisis de los distintos aspectos relacionados con la formación pedagógica de los estudiantes ${ }^{4}$ y surgió la inquietud del por qué en la práctica docente no se demuestra dominio, aplicación y comprensión real de la función docente por parte de los estudiantes.

Las acciones que se desprenden de este cuestionamiento tienen que ver con el empezar a proponer y ejecutar soluciones desde la óptica de la investigación educativa. Para el efecto se están desarrollando dos líneas de trabajo; una que se refiere a la práctica pedagógica y la otra que se refiere al trabajo de investigación del mismo Comité de Práctica.

En cuanto a la practica docente se refiere, estas acciones se plasman en definir como propósitos fundamentales de la práctica pedagógica en el Departamento de Biología reflexionar críticamente sobre la acción docente, basado en elementos de investigación educativa, analizar cada uno de los elementos que componen la realidad del espacio escolar, diseñar alternativas didácticas a problemas concretos detectados en la acción educativa y el que la práctica se realice a través de proyectos pedagógicos que retroalimenten los procesos de formación docente y a las instituciones donde ella se realiza ${ }^{5}$.

\footnotetext{
${ }^{2}$ CASTAÑO CUELLAR, N. C La educación en el contexto social, cultural y político contemporáneo. Ensayo. Octubre de 1995.

${ }^{3}$ Informe del Comité de Práctica. Taller de Reestructuración Curricular. Departamento de

Biología. Hemeroteca Nacional Noviembre de 1995

${ }^{4}$ Informe del Comité de Práctica. Julio 22 de 1996

${ }^{5}$ Comité de Práctica Documento interno que acoge las conclusiones del Taller de Reestructuración Curricular. Departamento de Biología Hemeroteca Nacional. Noviembre de 1995 
La otra acción planteada fue el diseño y ejecución de un proyecto de investigación que indagara por los imaginarios y cosmovisiones de los maestros en formación de la Licenciatura en Biología; qué piensan del país, de la Universidad Pedagógica Nacional, cuáles son sus afectos, cómo constituyen grupos, que imagen tienen del maestro. En fin, esta acción es la concreción de este sueño y este articulo muestra nuestra visión acerca de ellos, no como estudiantes, sino como personas que sienten, que proponen, que deciden, que tienen incertidumbres y certezas, que aman, que viven....

\section{EL PROBLEMA DE INVESTIGACIÓN}

Entre los puntos críticos a considerar en la formación del docente de Biología, se encuentran aspectos como el poco interés por el trabajo pedagógico y a falta de identificación con la profesión a medida que avanzan los semestres De igual manera la evolución pedagógica de los estudiantes no parece ser la adecuada para un buen ejercicio docente Estos aspectos se hacen más críticos cuando se desconocen sistemáticamente las características y creencias de los estudiantes en relación con aspectos afectivos y culturales, tales como el sentido que le dan a sus vidas, su visión de país... y en general sus cosmovisiones. la imagen que tienen de la función docente y de la educación, las relaciones que encuentran entre la disciplina biológica y la formación pedagógica, por ejemplo, las actitudes y aptitudes hacia el trabajo docente y las representaciones que tienen de la UPN

Indagar sobre el sentido de esta problemática nos permitirla avanzar en la proyección de un currículo sustentado racionalmente, en donde el propósito sea mejorar la calidad de la formación pedagógica, en consonancia con las características y los intereses de los maestros en formación y el deber ser de la UPN.

\section{METODOLOGÍA}

Para el desarrollo de este proyecto nos proponemos hacer una investigación de tipo etnográfico, lo cual implica en primera instancia el conocer y practicar el enfoque, por parte de los investigadores; de manera que develen su pensamiento en torno a los sujetos y a sus acciones, para evitar sesgos posteriores en la interpretación.

En una segunda instancia se trata de aproximarse a los sujetos y a las acciones, mediante técnicas que permitan la participación de la comunidad en general, como forma de darle validez y confiabilidad a los resultados de la investigación. La validez en este trabajo también se relaciona con a confrontación entre los hallazgos efectuados y la fundamentación teórica existente al respecto

\subsection{Las fuentes de información}

Los registros de observación de los aspectos relacionados con la cultura, la familia, la sexualidad el desarrollo intelectual, y las expectativas de vida, proceden de las siguientes fuentes.

- De los estudiantes que asisten a los Seminarios de Educación y Cultura y de Pedagogía y Conocimiento que dieron a conocer su propia reflexión, a cual fue complementada con la visión externa de ellos hacia ellas y viceversa, de su percepción en 
aspectos como la religiosidad y el sentido de lo político, de su participación como sujeto universitario y como ciudadano colombiano; de la vida familiar, sus vivencias y relaciones, del concepto de arte y su vinculación con la cultura, su práctica, su vida como espectador del arte, de su sexualidad y sus vivencias familiares,

- De entrevistas centradas en la narración que respondieron a cuestionamientos sobre expectativas de vida en torno a las preguntas qué quiero, qué puedo y qué temo ser, efectuadas a practicantes

- De los estudiantes que asisten a los Seminarios de Educación y Sociedad y de Pedagogía y Psicología con los cuales se analizaron aspectos relativos a la sexualidad, la afectividad y las expectativas de vida y con quienes se hicieron trabajos acerca del desarrollo intelectual, a través de reflexiones y charlas, ejercicios académicos (para el caso del desarrollo intelectual), conversaciones y observaciones en salidas de campo.

Los registros correspondientes a los aspectos relacionados con la educación la pedagogía el sentido del ser docente las expectativas profesionales y el programa de Licenciatura provienen de las siguientes fuentes:

- De la aplicación de tres encuestas distintas a estudiantes de primero segundo, cuarto, quinto, sexto, séptimo, octavo y noveno semestres a quince estudiantes de práctica y a dos estudiantes que están haciendo su trabajo de grado.

- Autobiografías que han escrito los estudiantes del Seminario de Pedagogía y Didáctica durante varios semestres.

- Talleres y charlas formales realizadas con cuatro alumnas de práctica docente

- Entrevistas y observaciones efectuadas a practicantes que desarrollaban sus proyectos pedagógicos.

La información correspondiente a las actitudes generales proviene de los registros de observación obtenidos en la denominada "cartelera interactiva", colocada en el Departamento de Biología, que invitaba a los estudiantes a plasmar sus puntos de vista acerca de temas de actualidad Además de lo escrito en la cartelera se conversó con estudiantes para explorar sus opiniones acerca de ella

\section{4. ¿CÓMO LOS VEMOS?}

\subsection{Aspectos relacionados con la cultura}

\section{1. 1 La religiosidad}

Se señala en términos generales que si bien la religiosidad y la práctica religiosa han cambiado, existen diferencias cuando hacemos distinción por género. En los jóvenes es claro que si bien algunos de ellos creen en la religión o tienen algunas creencias, no las practican, lo cual se expresa en "creo en Dios pero no soy religioso" y consideran que la religión más que una vivencia es una costumbre. 
Otra posición se refleja en la consideración de Dios como un ser que está ahí, y a quien se puede recurrir cuando se le necesita. "Creo en Dios cuando me conviene". "creo en Dios, a mi manera".

Una tercera posición corresponde a quienes están ubicados en el escepticismo y el radicalismo, se consideran ateos y afirman que sólo creen en lo que ven. Esta última posición la perciben sus compañeras cuando expresan que ellos no tienen ideas religiosas definidas" o hablan de la negación de los compañeros hacia el tema de Dios".

Las mujeres definen la religión como "la creencia en algo superior" "relacionado con hacer las cosas bien o mal" y que constituye "una necesidad para el hombre" Es una forma de reflexión que incluye los hechos históricos y la presencia de Dios en todas las cosas de la creación Al igual que los hombres, algunas no creen en Dios y no quieren ocupar su mente en este asunto; otro grupo cree firmemente en Dios y se manifiesta practicante

Sin embargo, no existe una constante en el comportamiento religioso de los universitarios, en algunos casos se reconoce una actitud utilitarista cuando se recurre a Dios, sólo si necesita de El.

Parecería que las jóvenes son en este aspecto más reflexivas que los varones, les dan un sentido ético y metafísico a sus posiciones. Ellos son más simplistas frente a lo religioso; no se detienen en planteamientos o concepciones del problema. "Hay una negación hacia el tema de Dios, aversión al tema" expresa una de las compañeras.

\subsubsection{El arte}

Respecto al arte y sus diversas manifestaciones hay que distinguir dos situaciones. Una es la participación pasiva, es decir el rol de espectador ante los hechos artísticos y en esto el campo es muy vasto; otra es la participación activa que se da cuando se es actor, ejecutante y practicante. Por las respuestas y testimonios, es evidente que la presencia en el primer caso, y la actuación en el segundo, son bastante limitados y ellas tienen más de expectativa que de realidad, "leo y quisiera ser escritor", "aunque dibujo mal, me considero un gran pintor", "pienso ser poeta". Estas respuestas aunque parecen broma, confirman lo dicho.

Parecería de otra manera, que el maravillarse ante las obras artísticas ha sido relegado por el asombro que producen los fenómenos de la naturaleza y los actos de los seres vivos. En una de las salidas que constantemente se hacen con los estudiantes, fue notorio que al visitar un museo, se quedaran absortos admirando el árbol que adorna el dentro de la casa e ignoraron las esculturas y pinturas que allí se exhibían.

La mayoría de los estudiantes, hombres y mujeres, cuando reflexionaron sobre sus escasas vivencias en el arte, encaminaron sus escritos a señalar la importancia del arte y su necesidad, con respuestas evasivas, tales como: "Es parte importante de la cultura", "cada uno de nosotros es arte", "existen posibilidades ilimitadas". Las mujeres dicen que "es la forma de escapar de lo cotidiano", "el arte se lleva en la sangre", "es la forma de expresar lo que se piensa".

Incluso en el desarrollo mismo de sus trabajos cotidianos se nota ausencia de lo estético y en los casos en los que se hace, provoca la ironía de los compañeros. El Digitalizado por RED ACADEMICA 
sentido de las actitudes estéticas parece incluso ausente como forma de autoestima, la tendencia parecería ser a mantener una condición de pobreza.

\subsection{Aspectos relacionados con la política}

Las respuestas sobre la política muestran el rechazo que sienten no tanto por la política vista como el arte de gobernar, sino parlas prácticas políticas tradicionales del país. Este motivo quizá sea el que los impulsa a expresar su escepticismo por ella.

Hay desconfianza en la democracia, pero sin embargo alguno se manifiesta liberal demócrata, afirma que "apoya las revoluciones..., pero no cree en la guerrilla ni en los que gobiernan, porque (dice) tienen equivocado su papel”.

Cuando se pregunta sobre política hay la tendencia a pensar en los partidos políticos y en los gobernantes, antes que en prácticas propias del contexto universitario. Aunque alguno de ellos afirma "no creer en las masas, en el sentido del montón, creo en las personas afirma que piensa en el cooperativismo como solución a problemas sociales, "el cooperativismo es como más fácil de manejar".

Las jóvenes consideran que la política es manejada casi exclusivamente por el hombre dadas las condiciones de sociedad machista en la cual se vive. Ellas consideran que los hombres tienen mayor credibilidad política por su activismo en los motines universitarios y porque son quienes asumen el liderazgo estudiantil; creen que los muchachos consideran la política como algo importante; además consideran que no hay política, sino "politiquería barata". Son ante todo espectadoras críticas, de ideas independientes, radicales, con posiciones que van desde "no creer" hasta considerar que la moral y la política van unidas, pero haciendo la salvedad de que la moral está antes que lo político y que el enfoque tradicional, que mantiene el statu quo es su referente.

Hay quienes consideran que la política no es de su gusto, pero tampoco le son indiferentes los acontecimientos que ésta con lleva. La indiferencia se genera al parecer porque no hay un conocimiento de ella; pero tampoco hay una acción política consciente que pretenda aportar de alguna manera a la transformación de las condiciones políticas de la Universidad Pedagógica Nacional ni del país.

\subsection{Aspectos relacionados con la familia}

\subsubsection{La imagen de ellos}

En este punto se comienza por tratar de entender cómo es la relación de los varones frente a su familia. En general no se encuentran apreciaciones donde se muestre una relación basada en las buenas relaciones entre padres y hermanos, parece que predominara una relación "buena pero distante", "sujeta al apoyo económico que se recibe"; se hacen afirmaciones del tipo "soy un individuo más del grupo que se llama familia".

Los siguientes planteamientos completan la imagen que se tiene de la familia: "mis relaciones son de conveniencia, nos soportamos "colaboro en los oficios de a casa porque tengo que retribuir en algo". 
La apreciación de las jóvenes respecto a la familia de sus compañeros son del tipo "afectivamente sus relaciones están dadas con sus amigos y la novia, más que con los padres". "son desprendidos del hogar y comparten la mayor parte de su tiempo con personas que no son de la familia". "son machistas en sus casas, con todo lo que esto implica, en el sentido de ser renuentes en la colaboración de los quehaceres del hogar" (sic). Cuando los hijos son mayores, son autoritarios y se consideran indispensables por ser ellos quienes dicen cómo se debe llevar la casa.

En términos generales ellas opinan que sus compañeros son muy reservados respecto a los asunto de sus familias y que no es habitual que las inviten a sus hogares, razón por la cual las apreciaciones sobre la vida familiar están dadas en las conversaciones informales que sostienen.

Sin embargo, se encuentran afirmaciones que demuestran afectividad hacia la familia. "en la casa todos somos muy sentimentales, incluso mi papá, le tenemos cariño a la vida, hay un sentido de sentimentalidad (sic). La gente por lo general no es así...".

\subsubsection{La imagen de ellas}

La percepción que ofrecen las respuestas de las estudiantes en torno a su familia tiene un cariz afectivo que se manifiesta en expresiones como, "en la casa me consienten" "busco dar amor y comprensión", "mi familia es mi apoyo emocional", expresiones que junto a frases como "son la parte emocional de mi vida" muestran claramente el sentido e importancia que tiene la familia para ellas.

En este contexto se mueven otras opiniones en torno al deseo de tener autoridad, de disponer de más tiempo para compartir con la familia, así como también la sensación de una cierta independencia que en el colegio no existe. Se es consciente de la dependencia económica, pero este aspecto no está determinando la relación familiar y sólo ocasionalmente colaboran en los quehaceres del hogar, teniendo como disculpa el trabajo universitario

Los jóvenes perciben que ellas, a medida que pasa el tiempo, tienden a manejar su vida de una manera autónoma.

\subsubsection{Ellos y ellas. Semejanzas y diferencias}

Al comparar la situación familiar de ellos y de ellas encontramos elementos comunes: no conocen detalles de la vida familiar de sus compañeras y compañeros; son dependientes económicamente de los padres; en diferente grado han logrado algún nivel de autonomía, aunque los hombres aventajan en esto.

Las diferencias estriban en que los hombres son alejados de sus hogares y las mujeres son más afectivas y quizá un poco sumisas; ellas viven una relación afectiva en su casa paterna y ellos con sus amigos o novias.

Estas imágenes parecen mostrar la reproducción de las tradiciones familiares y los roles que en la familia desempeñan hombres y mujeres. 


\subsection{Aspectos referidos a la sexualidad}

\subsubsection{Ellos}

La mayoría de os estudiantes tienen compañera o novia con la que pasan gran parte de su tiempo; son desinhibidos y sin tabúes inestables y machistas en su concepción de sexualidad. Aspectos que llevan a la creencia de que el hombre puede establecer relaciones promiscuas y esto lo hace más varón.

Son reservados frente al tema, manifestando "no tener interés en expresar por escrito lo que piensa o hace en torno a este tema", o por considerar que es "algo muy personal", Hay quienes reconocen ser muy desordenados en el manejo de su sexualidad cuando tienen relaciones con varias parejas en el mismo año.

Las jóvenes dicen de los muchachos que "pican aquí y allá hasta que encuentran a la persona adecuada para sus relaciones sexuales", que son inestables en sus relaciones de pareja, "mujeriegos y machistas en el trata", siendo sus prioridades "las relaciones sexuales". Son sin embargo, extrovertidos en la expresión de sus sentimientos. Ellos tienen mayor libertad que las mujeres y sus actitudes varían entre la brusquedad y el infantilismo. Impera, particularmente para los hombres, el doble sentido en sus conversaciones acerca de lo sexual. Seria interesante confrontar esta suposición con las expresiones que se encuentran en los baños de los hambres y que tienden a ser predominantemente sexuales genitales. En una de tales expresiones se habla de la "pedagogía del amor" en un dibujo que muestra explícitamente una relación coital. En otras expresiones es notable la relación casi indisoluble entre lo sexual coital y la agresión al otro.

En el plano afectivo se detecta una tendencia más o menos fuerte en ellos por establecer vínculos estrechos de amistad que implican relaciones de solidaridad, respeto y ayuda. Esta tendencia se genera fundamentalmente en grupos pequeños y en algunos casos, sólo con un otro independientemente de la condición de género.

\subsubsection{Ellas}

Las mujeres por su parte, parecen tener un sentido más integral de la sexualidad, no la limitan a la relación física pues le dan un valor especial a los sentimientos, la moral y la coquetería. Se observa al parecer una tendencia a mantener en la afectividad y en la sexualidad, los roles asignados culturalmente a cada género: ellas tienden a mantener ligadas las dimensiones afectivas y sexuales, mientras que ellos parecen hacer una ruptura valorativa en este sentido.

Las situaciones se matizan, desde la consideración de algunas de ellas acerca de llevar una vida sexual activa, desconociendo los parámetros de la sociedad machista. "Me parecen importantes las relaciones prematrimoniales" expresa una de ellas, a la vez que otra afirma que tiene una "vida sexual activa que comparte con el novio" o "en mis relaciones de pareja trato que todo salga bien, no tengo prejuicios y disfruto de mi y de los demás".

De otra parte, hay quienes se consideran muy conservadoras, "me respeto como mujer", "la vida sexual debe estar ligada a conceptos morales", "me gusta llevar las cosas con calma y mesura puesto que las relaciones pueden esperar", son expresiones que muestran la otra cara de la moneda. 
Los muchachos consideran a las chicas muy reservadas en este aspecto y firman que es poco realmente lo que saben de la vida sexual de sus compañeras; "las mujeres se preocupan más por su aspecto físico", "son vanidosas".

Sin embargo, de la lectura general de estas imágenes se podría deducir que si bien ellas saben practicar una cierta coquetería femenina, su glamour no es la preocupación central. Se consideran afectuosas, un tanto vanidosas y coquetas en cierta medida.

Podría decirse que si bien la mujer en las dos últimas décadas ha ganado en autonomía e independencia y se piensa que ya no está tan prejuiciada, maneja su sexualidad con parámetros morales inculcados en la familia, y continúa las tradiciones culturales. Así en las salidas de campo, por ejemplo, en las relaciones de pareja se hace más o menos evidente la reproducción de roles tradicionales y se confirma en cierto sentido lo que se observa en los pasillos de la Universidad: la imposición del autoritarismo del varón sobre la mujer es evidente.

Otras observaciones muestran que ellos y ellas tienden a ver la sexualidad como un problema. Asumen su sexualidad en términos muy complejos que generan, en buena parte de los casos, conflictos, según historias personales de inseguridad, super yo rígidos y hasta maltrato.

Existe para un grupo significativo de jóvenes, la incertidumbre de saber si se está ejerciendo adecuadamente la sexualidad o no, particularmente en los hombres, en lo relacionada can la que denominan la "técnica sexual" y en las mujeres, en si se debe acceder a las relaciones sexuales y de qué manera. Quizá esta incertidumbre se relaciona con las presiones de grupo que imponen de alguna manera "un estilo de vida" al cual se adaptan para no ser excluidos y marginados.

Existe en algunas el temor a establecer relaciones amorosas y sexuales con sus compañeros para no ser señaladas como "fáciles", puesta que se da también la tendencia en ellos a comentar sus aventuras amorosas; muchas, más producto de la invención y el deseo, que de experiencias reales. En tal sentido se puede observar en algunos casos, cierta prevención por parte de las mujeres hacia este tipo de relaciones, pues se considera que hay una reputación que cuidar, dadas las pautas de crianza y consideraciones de índole moral. Es necesario decir también que se forman constantemente parejas entre compañeros que han culminado en matrimonios oficiales.

Si bien no es una característica generalizada, se encuentran en ellos desconocimiento y algunas creencias que seguramente inciden en sus actitudes afectivas, que en ocasiones les ocasionan conflictos, relacionadas con la masturbación, la virginidad, la genitalidad y la homosexualidad.

No resulta una característica generalizada en ellas, pero es necesario citarla aquí, se refiere a cierto temor para expresar empatía hacia los demás, pues se tienen vivencias afectivas desagradables que se constituyen en barreras que obstaculizan las posibilidades de relación. En buena parte de estos casos se detecta un historial de maltrato y agresión

\subsection{Aspectos referentes a las expectativas de vida}

En términos generales se podría decir que estos jóvenes no alcanzan a imaginar una cosmovisión más o menos clara respecto a sus proyectos de vida. Se entiende que en el 
momento se encuentran en proceso de construcción de parámetros que puedan orientar su mirada hacia el futuro, pero es evidente la carencia de expectativas en a gran mayoría y la falta de interés por el acontecer social, cultural y político Parecería que una concepción del mundo y de la vida se limitara a un entorno muy reducido y altamente individualizado

En cuanto a los estudiantes que recién ingresan, una gran parte expresa que estudia licenciatura en biología para ser maestro. Otra buena parte se ve ejerciendo como docente aunque con reparos en cuanto al nivel o niveles educativos en los que se desempeñarían Inclusive algunos señalan no querer enseñar a niños pequeños

Se evidencia también, aunque pareciera contradictorio con planteamientos anteriores, una gran sensibilidad hacia las cosas de la vida cotidiana. Si bien no es general, sí es importante resaltar la sensibilidad de algunos de ellos y ellas por aspectos como la cultura, la estética, el otro, el amor y la alegría

\subsection{Aspectos relacionados con el desarrollo intelectual}

Para el caso de los estudiantes que ingresan en el primer semestre del año, se detecta un fuerte apego a la imagen del colegio. Casi todos terminaron sus estudios secundarios el año inmediatamente anterior, y en este sentido a algunos se les dificulta asumir el rol de estudiante universitario, particularmente en aspectos relacionados con su autonomía.

Al comparar esta situación con aquellos que ingresaron en el segundo semestre del año, se puede distinguir que generalmente son personas que han dejado de estudiar por algún tiempo y su actitud en este caso es diferente.

Se observa un desarrollo desigual en lo intelectual y aún en lo que podría llamarse madurez psicológica, la cual está relacionada con la historia y dinámica académica personales. Se hace notable en algunos, un mayor compromiso al asumir las responsabilidades académicas y parece que esta situación tiende a mantenerse en el transcurso de la carrera.

Se encuentra en otros, dificultades para realizar procesos de análisis y síntesis, incluso en cuarto semestre. Se considera al igual que en la anterior observación, que esta situación está relacionada con el historial académico de cada estudiante (metodología de estudio, referentes pedagógicos, entre otros).

Bastantes jóvenes presentan dificultades en su expresión escrita, en la lectura de textos con algún nivel de complejidad y en la argumentación. Para el caso de los estudiantes de primer semestre, son notorias las diferencias individuales, evidenciándose además el sentido de participación en las discusiones, el trabajo grupal, la consulta y en general la actitud académica que tiene que ver inclusive con el entusiasmo puesto en el desarrollo de las tareas.

Se detecta también en la mayoría de los cursos cierta pasividad en lo que se refiere a la toma de decisiones grupales. Se tiende a imponer la visión o la posición del líder a de grupos muy pequeños, sin que medie una discusión amplia. Para el caso de las salidas de campo es notable la influencia de los estudiantes de mayor edad y experiencia (?) quienes tienden a imponerse, en algunas ocasiones negativamente, en la medida en que generan actitudes no adecuadas. Sin embargo, se observa que en las actividades planeadas para 
las salidas de campo, los jóvenes asumen la responsabilidad académica y respetan los acuerdos de convivencia. Al respecto se puede pensar que si bien influyen pocos sobre el grupo, también se genera cierta independencia o quizá individualismo en el momento de realizar las diferentes actividades.

Parece ser que las estudiantes tienden a preocuparse más por su desarrollo académico e intelectual que los estudiantes. Se evidencia un mayor interés y capacidad de desenvolvimiento por parte de ellas en el plano intelectual.

\subsection{Aspectos relacionados con la educación}

\subsection{La pedagogía}

No se encontraron concepciones acerca de la pedagogía, sino ideas sobre la educación, que se refieren a considerarla como "la capacidad" o "el arte de enseñar", "medio de transmisión de conocimientos y de experiencias a personas ajenas" o como "aquella que forma a un individuo como persona". Estas ideas parecen reflejar el carácter pragmática que se le asigna a la educación y podrían ubicarse dentro de un conocimiento cotidiano.

\subsubsection{La investigación}

El concepto de investigación parece surgir del conocimiento parcial que se tiene de la investigación aplicada a las ciencias naturales y consideran el método científico como única alternativa. Esto permitiría entender planteamientos del tipo: "las características de la investigación son: objetivos, actividades, conclusiones, bibliografía y tiempo", "la investigación es encontrar una explicación de algo a través del método científico" o "la investigación en ciencias naturales utiliza procesos como observación, hipótesis y experimentación. Esto se lleva a nivel de laboratorio".

Así podría entenderse porqué la tendencia a valorar el conocimiento positivista, por qué los trabajos de grado por los que optan los estudiantes son principalmente en el área disciplinar y la poca mención a la investigación educativa.

Consideran que la investigación puede ser un área de desempeño profesional, sin embargo afirman que necesitan de mayor profundización. Algunos manifiestan la necesidad de conocer y manejar una metodología etnográfica para el trabajo en proyectos pedagógicos.

\section{7.3 Concepciones acerca del ser docente}

En las diferentes registros efectuados, aunque sean provenientes de distintas fuentes, se resaltan los mismos aspectos, así sean dichos de diferente manera. Se percibe la labor docente como una práctica instrumental. Tienen opiniones sobre lo que es un docente y un buen docente, para lo cual proponen textualmente características como:

- Tener un buen manejo del tema Que sepa su materia

- Tener buen maneo de grupo, lograr que los estudiantes no se dispersen.

- Saber motivar y manejar recursos didácticos para motivar 
- Saber evaluar, en términos de saber hacer preguntas saber observar. ser justos

- Interactuar y comprender a los alumnos.

- Influir en sus actitudes.

- Orientar, pero no obligar

- Ser exigente y franco.

Igualmente se señala como importante, desde el punto de vista de la psicología, la interacción afectiva y la capacidad de entender a los alumnos, de ayudarles a manejar sus conflictos y problemas de drogadicción, alcoholismo y sexualidad; así como hacer un "buen uso de la autoridad", entre otros.

No se encuentran referencias en cuanto a problemas del conocimiento, como parte de la labor docente. Esto podría indicar que funcionan bajo un modelo instruccionista y dado que su aprendizaje como docentes, proviene de los modelos que se desarrollan en el Departamento de Biología, podemos pensar que éstos son también instruccionistas.

Ante la pregunta ¿cómo se logra ser un buen docente? plantean que es en la práctica donde aprendieron lo que saben. La fundamentación teórica la presentan como incomprensible e inaplicable a la hora de interactuar con los grupos también se coincide en decir que la forma como ellos empezaron a efectuar su práctica docente, la aprendieron viendo a los docentes que les dictan clase en la Universidad, se toma generalmente un modelo básico, aún cuando a veces se tomen aspectos de otros.

Para todos es incuestionable que saber biología es fundamental para ejercer como Licenciado en Biología, pues afirman que les permite ser creativos, da seguridad en el manejo de los temas, se utilizan mejor los recursos y "no se enseñan cosas que no son". Puede ser aventurado decirlo, pero se percibe que la idea de que enseñar se refiere básicamente a enseñar contenidos.

No se muestran relaciones de la pedagogía y la labor docente con la cultura y aspectos políticos, económicos y sociales del país. Se reitera así el predominio de una visión local del mundo; imágenes coherentes con las imprecisiones mencionadas anteriormente acerca de la pedagogía.

Estos planteamientos parecen mostrar que "en el saber de los profesores y en particular en su dominio semántico, el término pedagogía es a la vez el más clara y el más confuso... Sí bien la diversidad de opiniones es una riqueza, a la hora de los acuerdos...nos encontramos con que cada quien tiene su opinión, siendo esto algo muy molesto para quienes consideramos que es la pedagogía el discurso que fundamenta nuestra oficio. Todo discurso se caracteriza por tener unidad, coherencia y rigurosidad en sus planteamientos"6.

\footnotetext{
${ }^{6}$ CHONA, G Documento de trabajo no publicado Julio de 1997 


\subsubsection{La Formación docente, el programa de la Licenciatura y las expectativas profesionales}

En general los estudiantes manifiestan no sentirse preparados para la labor docente y solicitan mayor exigencia. Hay manifestaciones de preocupación, tanto por el área pedagógica como por la disciplinar; se percatan claramente del desequilibrio entre lo disciplinar y lo pedagógico, la desventaja se aprecia en lo pedagógico. De manera contradictoria, el programa de formación lo describen básicamente enunciando asignaturas de la disciplina, la mayoría de ellos pasa por alto el área de pedagogía y didáctica. Un buen número de estudiantes no conoce el programa de estudios, otros se limitan a describir materias o núcleos básicos, no hay una visión integral del currículo.

Predomina el gusto, interés, motivación y valoración por el conocimiento biológico e incluso algunos manifiestan como fortaleza el estar bien preparados en biología, no así en pedagogía. Otros plantean la necesidad de profundizar en algunas áreas de la biología.

En relación con el área de pedagogía manifiestan que es la práctica docente la que les permite visualizar los problemas de la pedagogía En los seminarios la presentación de lo teórico no les posibilita relacionar con los problemas de la práctica, "sirve para su formación personal, pero no para ser docentes", no saben cómo aplicarlo a sus realidades: los seminarios dan visiones generales, otros no han servido, ni siquiera los recuerdo", "el que más sirve es pedagogía y didáctica Se acerca a las problemáticas del ejercicio docente", se hacen solicitudes de cambio de los seminarios para que "tengan que ver más con la realidad docente".

Tampoco se encuentra la relación de la disciplina con lo docente y mencionan como debilidad no saber cómo manejar los diferentes temas a nivel de clase. Se presenta como generalidad el que pese a que se critican modelos de enseñanza tradicional, al realizar su práctica siguen utilizando esos mismos modelos, "no tengo herramientas para cambiar" afirma alguno de ellos. "Se crítica el premio o el castigo, pero hago uso de ellos para mantener la atención de los alumnos", "critico la forma de autoridad de algunos maestros que he tenido en la universidad, pero termino siendo un ogro peor...". Algunos expresan resentimiento hacia profesores en particular, así como aluden a las manifestaciones de autoritarismo e incluso de maltrato e irrespeto.

Resaltan que es en la práctica docente donde ven la complejidad del trabajo en la escuela, lo poco preparados que están para asumirlo y comprender aspectos de los niños a los cuales dicen, no conocer realmente. $Y$ finalmente plantean la necesidad de una mayor profundización en lo pedagógico, "conocer teorías de actualidad como aprendizaje significativo, constructivismo, mapas conceptuales, etc.".

Es reiterativa la crítica al hecho de que solo se tenga contacto con la escuela a partir de séptimo semestre y la insistencia en proponer iniciar "ojalá desde primer semestre" porque se les permitiría asumir como docentes durante toda la carrera y "no darse un duro golpe casi al terminarla".

Respecto a las expectativas que tienen coma profesionales, paradójicamente la mayoría proyecta su profesión hacia la docencia, muy pocas hacia la investigación en biología y cuando se les inquiere por el aporte que pueden hacerle al país, todos se centran en la formación de los jóvenes y en propiciar el desarrollo nacional "para un futuro mejor". 


\section{ALGUNAS CONCLUSIONES PROVISIONALES}

Se vislumbra la condición de jóvenes que sostienen y continúan las tradiciones y tradicionalismos culturales y que no se permiten pensar en la existencia de rupturas de los estereotipos culturales existentes. Es así como en la diferenciación de roles, por ejemplo, se mantienen los estereotipos que se asignan a lo femenino y a lo masculino; en lo educativo el pensamiento es eminentemente clásico y aún en aspectos como las relaciones de poder se continúan mostrando las asignaciones de autoridad maestroalumnos.

Parece emerger una imagen y un predominio de lo individual en lo que se relaciona con los aspectos político, religioso y en cuanto a expectativas de vida que no trascienden más allá del bienestar y de las necesidades personales. No se encuentran en términos generales ideales explícitos que muestren preocupación par imaginarse y trascender en la sociedad, aunque la profesión docente así lo exija.

Posiblemente ese individualismo influya en una tendencia hacia la heteronomía en lo que respecta a liderazgo y toma de decisiones y habría que pensar en que quizás estos chicos se encuentren ante el desconocimiento o negación de lo colectivo, aspecto de ninguna manera deseable para el ejercicio docente.

Se vislumbra en las expectativas de vida un pensamiento inmediatista y concreto, una visión local del mundo, que imita el acceso a lo utópico e imaginario, hacia una visión de futuro y una concepción de lo universal y abstracto; parecería que les es difícil ubicarse en el plano de lo irreal e hipotético.

Parece predominar un tipo de pensamiento analítico que conduce a la búsqueda de respuestas y soluciones instrumentales, haciendo complejo el relacionar la teoría con la práctica y posiblemente limitando otros procesos de desarrollo del pensamiento lógico que conducen por ejemplo, a la concepción de lo sintético.

La formación profesional la limitan a lo estrictamente académico, su relación con las diversas manifestaciones culturales es casi inexistente y no se encuentran concepciones explicitas que liguen el aspecto educativo con el cultural. Podría pensarse que aquellos aspectos humanísticos que podrían incidir en el desarrollo como personas y como docentes, pareciera les son ajenos, manteniendo en ellos la condición de "analfabetas culturales".

Detrás de las observaciones y comentarios que se hacen respecto a lo educativo no existen argumentos que los sustenten, mostrando espontaneidad e intuición. En este mismo sentido se observa una tendencia a considerar la pedagogía como una acción técnica puramente instrumental y parece claro que los estudiantes no se consideran preparados para la docencia, al menos cuando se enfrentan a la práctica; piensan que la pedagogía se aprende haciendo.

No hay imágenes claras acerca de la investigación; se mencionan solo las de tipo experimental aplicadas a las ciencias naturales y asociadas a profesores o a líneas de trabajo concretas Incluso se deja entrever una tendencia conceptual que traslada la consideración experimental de las ciencias naturales hacía las relaciones interpersonales 
Se presenta desconocimiento del programa de formación, se tiene una visión semestralizada y poco integrada Las posibilidades de acción docente se restringen casi exclusivamente al aula de clase y sólo se considera el campo de la educación básica

En este contexto creemos que es necesario contribuir a la construcción de nuevos imaginarios que hagan pasible una visión del mundo y de la vida mucha más amplía, desde un concepto de lo universal y de lo nacional.

Es necesario igualmente, generar unas elementos culturales que den paso a la autonomía, al compromiso y a la expresión de la singularidad en contraposición al individualismo exagerado. Hablamos de la singularidad en el sentido de reconocimiento del otro, de la responsabilidad y la reciprocidad con el otro y definimos al otro, no como objeto experimentable, sino como parte fundamental de mi relación ${ }^{7}$. Debemos reconocer paralelamente que somos singulares y también sociales; para el efecto es necesario aportar las bases para la construcción de una conciencia colectiva que admita la singularidad y que no pretenda la homogenización de las conciencias y de las actitudes

Concretar en acciones lo que significa universidad, lo Universal, abrir espacios que contribuyan a desarrollar una visión de lo cultural lo cual implica, descentrarnos de la transmisión de contenidos y dar vía libre a las potencialidades de cada cual, de modo que el aula pase a ser un lugar de encuentro dialógíco y de construcción intersubjetiva ${ }^{8}$. El Departamento de Biología debe lograr "una sólida vinculación con la vida de los sujetos comprometidos en el, reconocer las permanentes transformaciones culturales en valores, estilos de relación, concepciones, sentidos y lenguajes que tienen lugar en la cotidianidad. más allá de(sus) muros"9.

Es urgente entonces, generar un discurso pedagógico coherente, explicitar las intencionalidades del ejercicio pedagógico como crítica al pensamiento docente intuitivo y espontáneo que nos hace perder el contacto y el sentido de la realidad

\section{BIBLIOGRAFIA}

ALZATE MEDINA, G. y otros. 1995. La cultura fracturada. Ensayos sobre la adolescencia colombiana. Tomo I. En: Proyecto Atlántida. Estudio sobre el adolescente escolar en Colombia. Fundación FES-COLCIENCIAS TM Editores: Bogotá.

ANTIA DE CABRERA. M.T. 1994. La Universidad Adolescente Fondo Resurgir-FES. Ed. FES Cali

CASTAÑO CULLAR N.C. Un currículum de ciencias naturales para a educación básica primaria o el, papel del conocimiento biológico en la educación de los niños. Ponencia

\footnotetext{
${ }^{7}$ CASTAÑO, N.C. Un curriculum de ciencias naturales para la educación básica primaria o el papel del conocimiento biológico en la educación de los niños. Ponencia en el Seminario Nacional sobre la construcción de un currículo en ciencias naturales para la educación Básica y Media Universidad del Valle Cali. Noviembre de 1997.

${ }^{8}$ CASTAÑO N.C. ¿El maestro que necesita el país o qué somos y qué queremos ser? Ponencia en el panel. "El maestro que el país necesita". Universidad Pedagógica Nacional Depto de Biología. Mayo de 1996.

${ }^{9}$ lbid
} 
en el Seminario Nacional sobre la construcción de un currículo en ciencias naturales para la educación Básica y Media Universidad del Valle. Cali Noviembre de 1997

La educación en el contexto social, cultural y político contemporáneo. Ensayo Octubre de 1995

. El maestro que necesita el país o que somos y qué debemos ser? Ponencia en el panel el maestro que el país necesita. Universidad Pedagógica Nacional. Depto. de Biología. Mayo de 1996.

COMITE DE PRACTICA Documento interno de trabajo que acoge las conclusiones del Taller de Reestructuración Curricular Hemeroteca Nacional. Departamento de Biología. Noviembre de 1995. Informe presentado al Taller de Reestructuración Curricular Hemeroteca Nacional. Departamento de Biología. Noviembre de 1995 . Informe de Julio 22 de 1996.

COMITE DE REESTRUCTURACIÓN. Informe del I semestre de 1995.

CHONA DUARTE, G. Documento de trabajo no publicado. Julio de 1997.

STENHOUSE, L 1991. Investigación y Desarrollo del Currículum. Tercera edición. Morata Madrid. 